\title{
Measurements of thermal Transmittance of an External massive timber wall in-situ and in the Laboratory
}

\author{
Christoph Geyer ${ }^{1, *}$, Andreas Müller ${ }^{1}$, and Barbara Wehle ${ }^{1}$ \\ ${ }^{1}$ Bern University of Applied Sciences, Solothurnstr. 102, CH-2500 Biel/Bienne, Switzerland
}

\begin{abstract}
The thermal transmittance of an exterior massive timber wall was measured in situ in Appenzell, Switzerland according to the standard ISO 9869-1. The measurements were performed with two different measurement sets in parallel. The measurements started in February and stopped at end of April. The measuring data were analyzed using mean values of the thermal transmittance coefficient and of the thermal resistance following the procedure of ISO 9869-1. In order to clarify if the in-situ measurement results show significant deviations from the measurement results of the thermal transmittance obtained in the laboratory, the thermal transmittance of the identical wall construction was measured in the laboratory of Bern University of Applied Sciences in Biel according to the standard EN ISO 8990 for steady state boundary conditions in a guarded and calibrated hot box. The test results will be presented and the measurement setup will be described. The calculation value of the thermal transmittance coefficient of the massive timber wall according to EN ISO 6946 is $\mathrm{U}=0.53 \mathrm{~W} /\left(\mathrm{m}^{2} \mathrm{~K}\right)$. The test results of the thermal transmittance coefficient, U-value of the wall, measured in the hot box, agreed well within a confidence level of $95 \%$ with the calculated value. The in-situ measurement results of the thermal transmittance coefficient of the two measurement sets differ significantly in the order of $8 \%$ referred to the calculated U-value of the wall as the basic amount. Furthermore, both in situ test results of the U-value of the wall show significant deviations from the calculated U-value up to $27 \%$.
\end{abstract}

\section{Introduction}

Nearly four fifth of the buildings of the building stock in Switzerland were erected before the year 1990 [1]. The thermal protection of the envelope of these buildings is much less than the required quality level of today's energy economy standards. To reduce the emission of greenhouse gases, the thermal protection of these buildings has to be increased. To develop efficient solutions to improve the thermal protection it is necessary to know the parameters of the existing external construction elements like the thermal transmittance coefficient, U-value. But unfortunately, there is a lack of information of these parameters. This leads to a great demand to determine the thermal transmittance of external construction elements in-situ.

To investigate the uncertainty and the reliability of two different measurement sets, which are available in Switzerland, we measured the thermal transmittance of a massive timber wall insitu and in the laboratory.

\section{Measurements}

The in-situ measurement took place at the production site of Nägeli Holzbau in Gais, Switzerland. We installed the test specimen in the north wall of the production hall.

\subsection{Construction of the Massive timber wall}

The massive timber wall consists of five layers of wooden boards, made of spruce, which are fixed to each other by beech plugs without any glue. The orientation of the boards of each layer is turned by $45^{\circ}$. The total thickness of the test specimen wall is $150 \mathrm{~mm}$.

The construction of the test specimen wall is shown in Table 1.

\footnotetext{
* Corresponding author: Christoph Geyer, Christoph.geyer@bfh.ch
} 
Table 1. Construction layers of the test specimen wall. The figure on top shows a vertical cross section of the wall from [2]. The list at the bottom describes the construction layers of the test specimen wall from outside to inside

\begin{tabular}{|l|}
\hline \\
- $30 \mathrm{~mm}$ Spruce boards \\
- $1 \mathrm{~mm}$ Airgap \\
- $30 \mathrm{~mm}$ Spruce boards \\
- $1 \mathrm{~mm}$ Airgap \\
- $30 \mathrm{~mm}$ Spruce boards \\
- $1 \mathrm{~mm}$ Airgap \\
- $30 \mathrm{~mm}$ Sind-proof sealing sheeting \\
- $1 \mathrm{~mm}$ Airgap boards \\
- $30 \mathrm{~mm}$ Spruce boards
\end{tabular}

\subsection{In-situ measurement method}

To measure the thermal resistance $\mathrm{R}$ and the thermal transmittance $\mathrm{U}$, we use the heat flow meter method according to the standard ISO 9869-1, edition 2014-0801 [3].

The heat flow density through the internal surface of the test specimen wall, $\mathrm{q}\left(\mathrm{t}_{\mathrm{n}}\right)$ at time $\mathrm{t}_{\mathrm{n}}$ is measured by a heat flow meter. Parallel, the internal and external air temperature, $\mathrm{T}_{\mathrm{i}}\left(\mathrm{t}_{\mathrm{n}}\right)$ and $\mathrm{T}_{\mathrm{e}}\left(\mathrm{t}_{\mathrm{n}}\right)$, are measured.

The thermal transmittance of the test specimen wall at that point of time, $\mathrm{U}\left(\mathrm{t}_{\mathrm{n}}\right)$ is given by

$$
\mathrm{U}\left(\mathrm{t}_{\mathrm{n}}\right)=\mathrm{q}\left(\mathrm{t}_{\mathrm{n}}\right) /\left(\mathrm{T}_{\mathrm{i}}\left(\mathrm{t}_{\mathrm{n}}\right)-\mathrm{T}_{\mathrm{e}}\left(\mathrm{t}_{\mathrm{n}}\right)\right) \text { in } \mathrm{W} /\left(\mathrm{m}^{2} \mathrm{~K}\right)
$$

The measurement value of the thermal transmittance, $\mathrm{U}_{\text {ISO }}$ for a measurement period is calculated by dividing the mean of the heat flow density q by the mean of the temperature difference of the internal and the external air temperature, $\mathrm{T}_{\mathrm{i}}-\mathrm{T}_{\mathrm{e}}$,

In addition, with one measurement set of Ahlborn, the internal and external surface temperature, $\mathrm{T}_{\mathrm{si}}\left(\mathrm{t}_{\mathrm{n}}\right)$ and $\mathrm{T}_{\mathrm{se}}\left(\mathrm{t}_{\mathrm{n}}\right)$, are measured. With this measurement values one can calculate the thermal resistance of the test specimen wall at that point of time:

$\mathrm{R}\left(\mathrm{t}_{\mathrm{n}}\right)=\left(\mathrm{T}_{\mathrm{si}}\left(\mathrm{t}_{\mathrm{n}}\right)-\mathrm{T}_{\mathrm{se}}\left(\mathrm{t}_{\mathrm{n}}\right)\right) / \mathrm{q}\left(\mathrm{t}_{\mathrm{n}}\right)$ in $\mathrm{m}^{2} \mathrm{~K} / \mathrm{W}$

The measurement value of the thermal resistance, RISO for a measurement period is calculated by dividing the mean of the temperature difference of the internal and the external surface temperature, $\mathrm{T}_{\mathrm{si}}-\mathrm{T}_{\mathrm{se}}$ by the mean of the heat flow density q.

\subsection{In-situ measurement sets}

The in-situ measurement of the thermal transmittance of the test specimen wall is performed with two measurement sets simultaneously.

We use two in-situ measurement sets:

- a gSKIN® measurement set of greenTEG AG, Zurich

- and an Almemo® measurement set of Ahlborn Messund Regelungstechnik GmbH, Holzkirchen.

The gSKIN ${ }^{\circledR}$ measurement set consists of a data logger, a heat flow meter and two Pt100 sensors for the measurement of the air temperatures inside and outside.

The Almemo ${ }^{\circledR}$ measurement set consists of a data logger, a heat flow meter but four sensors for the measurement of the surface and air temperatures inside and outside of the test specimen wall.

The plate of the heat flow meter is mounted at the internal side of the test specimen wall for both measurement sets.

For the Almemo measurement set two thermocouple sensors were fixed at the internal and the external surface of the test specimen wall to measure the surface temperatures.

All sensors for the measurement of the external air temperature are equipped with a weather and radiation protection, well known from meteorology stations, which are not included in the measurement sets.

\subsection{In-situ measurement results}

For the analysis of the measurements we do not use the software, which is delivered by both producers of the measurement sets.

The thermal transmittance, UISO and thermal resistance $\mathrm{R}_{\mathrm{ISO}}$ of the test specimen wall are calculated using equation (1) respective (2).

Measurement values are only accepted, if they fulfill the four requirements given by ISO 9869-1:

- the measurement period has to be longer than 3 days

- the measurement period has to be an integral multiple of $24 \mathrm{~h}$

- the difference of the measurement value at the end of the measurement period and $24 \mathrm{~h}$ before has to be less than $5 \%$

- the difference of the measurement value at the end of the measurement period and at two third of the measurement period must not exceed $5 \%$

The in-situ measurement started at $9^{\text {th }}$ of February 2018 and ended at $20^{\text {th }}$ of April 2018.

Figure 1 shows the in-situ thermal transmittance of the test specimen wall in terms of the values at a time $\mathrm{U}(\mathrm{t})$ and the mean of the measurement period according to ISO 9869-1 UISO $(\mathrm{t})$, measured with the Almemo measurement set. The above-mentioned acceptance requirements are not considered. 


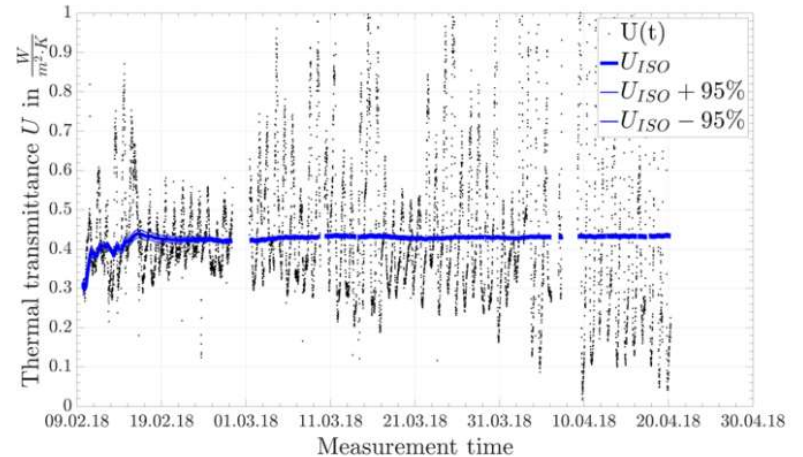

Figure 1. In-situ measurement values of the thermal transmittance of the test specimen wall in terms of the value at time $\mathrm{U}(\mathrm{t})$ (dots) and the mean value according to ISO 9869-1 UIso(t) (thick line). The thin lines denote the $95 \%$ confidence interval of the mean value

Figure 2 demonstrates the small influence of the acceptance criteria on the mean values of the thermal transmittance of the test specimen wall according to ISO 9869-1. The acceptance criteria affect only at the beginning of the measurement period the measurement results.

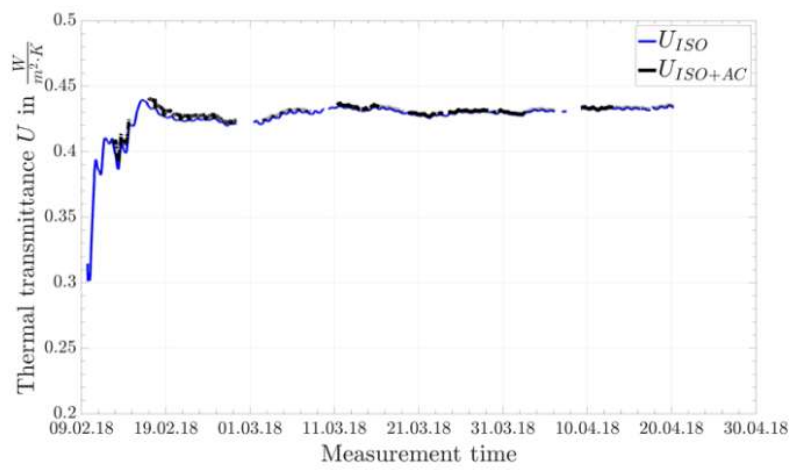

Figure 2. In-situ measurement values of the thermal transmittance of the test specimen wall in terms of the mean value according to ISO 9869-1 of the Almemo measurement set without considering the acceptance criteria $U_{I S O}(t)$ (slim line) and with consideration of the acceptance criteria $\mathrm{U}_{\mathrm{ISO}+\mathrm{AC}}(\mathrm{t})$ (thick line)

Table 2 summarizes the in-situ measurement results for the thermal transmittance, $\mathrm{U}_{\mathrm{ISO}}$, and the thermal resistance, $\mathrm{R}_{\mathrm{ISO}}$, considering all four requirements of ISO 9869-1 for the measurement period from 9.2.2018 to 20.04.2018. The errors of the measurement are given as $95 \%$ confidence intervals.

Table 2. In-situ measurement results for the thermal transmittance, $\mathrm{U}_{\mathrm{ISO}}$, and the thermal resistance, $\mathrm{R}_{\mathrm{ISO}}$, of the test specimen wall

\begin{tabular}{|c|c|c|c|}
\hline & Almemo & gSKIN & Difference \\
\hline $\begin{array}{c}\text { UISO in } \\
\mathrm{W} / \mathrm{m}^{2} \mathrm{~K} \\
)\end{array}$ & $0.431 \pm 0.006$ & $0.387 \pm 0.0092$ & $0.044 \pm 0.011$ \\
\hline $\begin{array}{c}\text { RISO in } \\
\mathrm{m}^{2} \mathrm{~K} / \mathrm{W}\end{array}$ & $1.98 \pm 0.017$ & & \\
\hline
\end{tabular}

By measuring the internal surface temperature of the test specimen wall, it is possible to determine the internal heat transfer resistance $R_{\mathrm{si}}$ in-situ. The internal heat transfer resistance at time $t_{n}$ is given by

$R_{s i}\left(t_{n}\right)=\left(T_{i}\left(t_{n}\right)-T_{s 1}\left(t_{n}\right)\right) / q\left(t_{n}\right)$ in $m^{2} K / W$

Where $\mathrm{T}_{\mathrm{i}}\left(\mathrm{t}_{\mathrm{n}}\right)$ denotes the internal air temperature, $\mathrm{T}_{\mathrm{si}}\left(\mathrm{t}_{\mathrm{n}}\right)$ the temperature of the internal surface of the test specimen wall and $\mathrm{q}\left(\mathrm{t}_{\mathrm{n}}\right)$ the heat flow density at his time. Again, the mean of the internal heat transfer resistance is calculated according the procedure of ISO 9869-1 by dividing the mean of the difference between the internal air temperature and the internal surface temperature by the mean of the heat flow density.

The in-situ measurement value of the internal heat transfer resistance is $R_{s i}=(0.153 \pm 0.004) \mathrm{m}^{2} \mathrm{~K} / \mathrm{W}$.

\subsection{Measurement in the Laboratory}

The thermal transmittance of a second test specimen of the massive timber wall was measured in a hot box according to EN ISO 8990 [4].

The thermal transmission of the test specimen wall is measured for three temperatures in the middle of the test specimen wall of $5^{\circ} \mathrm{C}, 10^{\circ} \mathrm{C}$ and $15^{\circ} \mathrm{C}$.

Table 3 shows the measurement results of the thermal transmittance, measured in the hot box. The errors of the measurement are given as $95 \%$ confidence intervals.

Table 3. Laboratory Measurement results for the thermal transmittance, $\mathrm{U}$, of the test specimen wall, measured in the hot box for three temperatures in the middle of the test specimen

\begin{tabular}{|c|c|c|c|}
\hline & $\mathbf{5}^{\circ} \mathbf{C}$ & $\mathbf{1 0}^{\circ} \mathbf{C}$ & $\mathbf{1 5}^{\circ} \mathbf{C}$ \\
\hline $\begin{array}{c}\mathrm{U} \text { in } \\
\mathrm{W} /\left(\mathrm{m}^{2} \mathrm{~K}\right. \\
)\end{array}$ & $0.53 \pm 0.02$ & $0.55 \pm 0.03$ & $0.52 \pm 0.05$ \\
\hline
\end{tabular}

\subsection{Calculation value of the thermal transmittance}

The calculation values for the thermal transmittance and the thermal resistance of the test specimen wall are calculated according to EN ISO 6946 [5] to $\mathrm{R}=1.17 \mathrm{~m}^{2} \mathrm{~K} / \mathrm{W}$ and to $\mathrm{U}=0.53 \mathrm{~W} /\left(\mathrm{m}^{2} \mathrm{~K}\right)$.

The calculations were done with the radial and transversal thermal conductivity of spruce of $\lambda_{\text {rad }}=0.09 \mathrm{~W} /(\mathrm{mK})$ and $\lambda_{\text {trans }}=0.07 \mathrm{~W} /(\mathrm{mK})$ given by Sonderegger et al [6].

\subsection{Comparison of the measurement results}

Figure 3 summarizes the measurement results in-situ, in the laboratory and the calculation value of the thermal transmittance of the test specimen wall. The error bars denote the $95 \%$ confidence intervals of the mean values. 


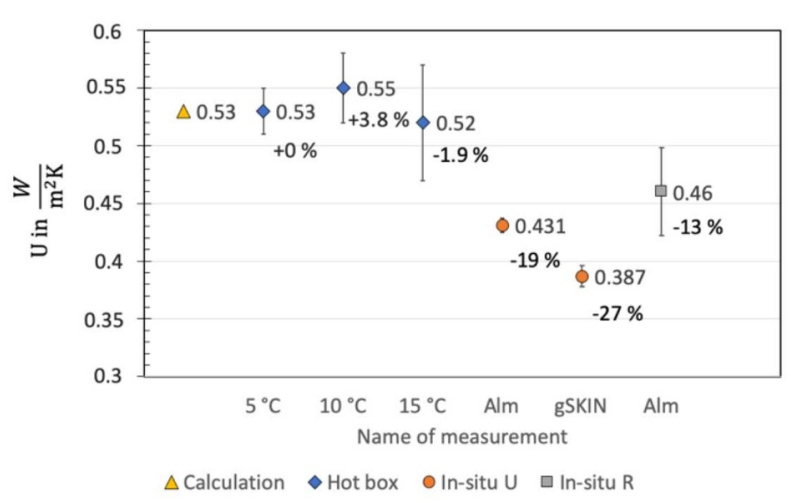

Figure 3. Calculated value (triangle), measurement values in the hot box (rhombus) at $5^{\circ} \mathrm{C}, 10^{\circ} \mathrm{C}$ and $15^{\circ} \mathrm{C}$ middle temperature, in-situ measurement values (circles) with the Almemo (Alm) and gSKIN measurement set and in-situ measurement value calculated from the thermal resistance measured with the Almemo measurement device (square). The deviation between the calculation value and the measurement values are given in percent of the calculation value. The numbers to the right of the markers denote the U-value in $\mathrm{W} /\left(\mathrm{m}^{2} \mathrm{~K}\right)$

Figure 3 demonstrates that the measurement results in the hot box agree well with the calculated value of the thermal transmittance of the test specimen wall.

Regarding the measurement results in table 2 and in figure 3 it is obvious, that there is a significant difference of $8 \%$ of the calculated value between the in-situ measurement results of the two measurement sets, Almemo and gSKIN.

In addition, there is even a higher discrepancy between the in-situ measurement results and the calculated value of the thermal transmittance of the test specimen wall, referred to the calculated value, of $-27 \%$ for the gSKIN and of $-19 \%$ for the Almemo measurement device.

The difference between the in-situ measurement values and the calculation value can be minimized by measuring the thermal resistance of the test specimen wall, RISo, instead of the thermal transmittance UISo insitu. The thermal transmittance is calculated using the following equation:

$\mathrm{U}_{\text {Standard }}=1 /\left(\mathrm{R}_{\mathrm{Si}}+\mathrm{R}_{\mathrm{ISO}}+\mathrm{R}_{\mathrm{Se}}\right)$

Where $\mathrm{R}_{\mathrm{si}}=0.17 \mathrm{~m}^{2} \mathrm{~K} / \mathrm{W}$ and $\mathrm{R}_{\mathrm{se}}=0.04 \mathrm{~m}^{2} \mathrm{~K} / \mathrm{W}$ denote the standard values of the internal and external heat transfer resistance.

The thermal transmittance, calculated by this method leads to a reduction of the difference between the calculation value and the in-situ measurement value of the thermal transmittance of $6 \%$ as can be seen in Figure 3.

\section{Discussion and Conclusions}

The in-situ measurement values for the thermal transmittance of the massive timber wall of the in-situ measurements differ significantly from the measurement values in the laboratory and from the calculation value. There are two reasons for this deviation.

The first reason is a non-perfect thermal contact between the heat flow meter and the surface. We could reproduce this effect by testing the in-situ measurement sets in the hot box.

This leads to the requirement, that it is necessary to use heat conductive paste or a conductive mat to optimize the thermal contact between the heat flow meter and the test specimen wall.

The second reason are values of the internal and external heat transfer resistance in-situ which are different from the standard values in the laboratory measurement and in the calculation and which change during the measurement period.

The influence of these heat transfer resistances in-situ can be minimized by measuring the thermal resistance $\mathrm{R}_{\mathrm{ISO}}$ of the test specimen according to equation 2 instead of the thermal transmittance UISO and calculate the standard thermal transmittance Ustandard according to equation 4.

To be sure to measure the external air temperature it is necessary to install the temperature sensor in a weather and radiation protection.

The uncertainty of the mean of the thermal transmittance according to ISO 9869-1 is much too low and cannot represent the systematic errors of the in-situ measurement values during the measurement period.

One observes a time dependent drift of the in-situmeasurement values of the thermal transmittance of the specimen wall during the measurement period. This drift cannot be corrected by using the acceptance requirements to the measurement values according to ISO 9869-1.

Figure 4 shows the in-situ measurement values of the thermal transmittance of the specimen wall for four different measurement periods compared with the in-situ measurement value of the whole measurement period, measured with the Almemo measurement set. The error bars of the measurement denote the $95 \%$ confidence interval of the mean values.

The in-situ measurement values of the thermal transmittance of the test specimen wall differ by up to $8.6 \%$ depending on the different measurement periods.

We suppose the origin of this effect in the fastchanging weather parameters during the measurement period in combination with the thermal capacity of the test specimen wall.

Therefor we recommend combining the in-situ measurement with a weather station to find possible correlations between the weather parameters like radiation, wind and rainfall and the in-situ measurement value of the thermal transmittance. 


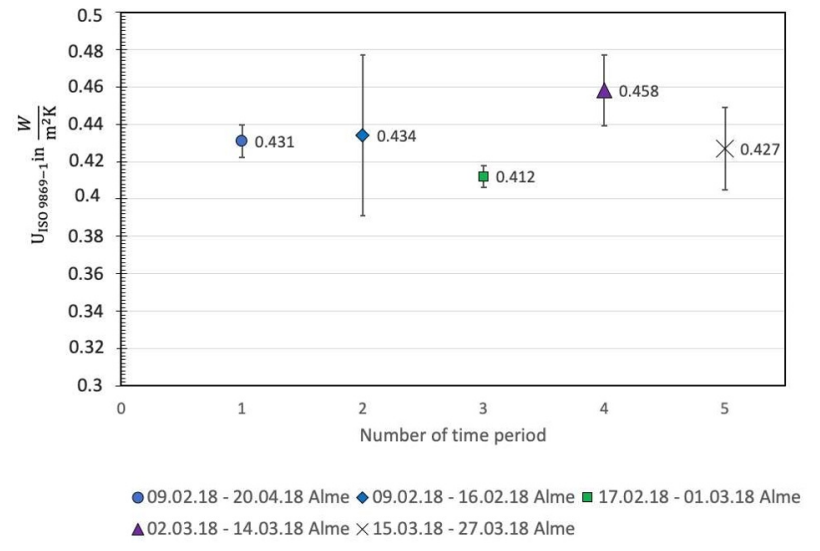

Figure 4. In-situ measurement value of the thermal transmittance of the test specimen wall of the whole time period (circle) compared with the in-situ measurement value of the thermal transmittance of the time period 09.02.18 16.02.18 (rhombus), of the time period 17.02.18 - 01.03.18 (square), of the time period 02.03.18 - 14.03.18 (triangle) and the time period 15.03.18 - 27.03.18 (cross). The numbers to the right of the markers denote the U-value in $\mathrm{W} /\left(\mathrm{m}^{2} \mathrm{~K}\right)$. The error bars represent the $95 \%$ confidence interval

We want to thank the Swiss Federal office for Environment for the funding of the project. The industrial partners TWOODS GmbH, 9056 Gais, Switzerland, Ahlborn Mess- und Regelungstechnik GmbH, Holzkirchen, Germany and greenTEG AG, Zurich, Switzerland for the support of the project.

\section{References}

1. Swiss Federal Statistical Office, (2014)

2. Nägeli Holzbau Schweiz, 9056 Gais, Switzerland

3. ISO 9869-1 Thermal insulation - Building elements - In-situ measurement of thermal resistance and thermal transmittance - Part 1: Heat flow meter method, International organization for standardization, (2014)

4. EN ISO 8990 Thermal insulation Determination of steady-state thermal transmission properties - Calibrated and guarded hot box

5. EN ISO 6946 Building Components and Building elements - Calculation methods, International organization for standardization, (2017)

6. W. Sonderegger, S. Hering and P. Niemtz.: Holzforschung, Vol. 65, pp. 369-375 (2011) 